\title{
La Periódico-manía y la prensa madrileña en el Trienio Liberal (I)
}

ENRIQUE RUBIO CREMADES

Universidad de Alicante

La Periódico-manía, publicación madrileña de los años 1820 y 1821 , nace a raíz del decreto que sobre libertad de imprenta llevó a cabo el gobierno de Fernando VII. El nueve de marzo de 1820 el monarca juraba la Constitución y un día más tarde publicó un Manifiesto en el que no sólo indicaba su respeto y acatamiento a la Constitución, sino que también instaba al pueblo español a que se comportara con sabiduría, orden y moderación, a fin de ser ejemplo de la Europa civilizada. Propósitos no cumplidos, pues si el período constitucional nace de un río de revueltas y sublevaciones, el efímero Trienio Liberal dará paso a uno de los más tristes y luctuosos episodios de nuestro siglo XIX: la ominosa década.

Bajo este telón de fondo, La Periódico-manía irrumpe en los albores del citado Trienio Liberal con un fin primordial: analizar todos los folletos, papeles y periódicos de los años 1820 y 1821 . Es, pues, este periódico de gran importancia para conocer los vaivenes de la prensa de la época, de tal suerte que sirve como pieza fundamental para el estudio de las sucesivas apariciones y desapariciones de los periódicos del momento, su duración, ideo- 
logía, formato y disposición, así como el motivo esencial que impulsó a políticos y escritores en general a editar su respectivo periódico.

La relación de publicaciones que ofrece La Periódico-manía es copiosísima y puntual, de ahí que fuera consultada en el siglo pasado por don Eugenio Hartzenbusch en su conocido trabajo Apuntes para un catálogo de periódicos madrileños desde el año 1661 al $1870^{1}$. Dicho crítico utiliza como fuente bibliográfica el citado periódico ya que se trata de un documento imprescindible para el estudio de la prensa del Trienio Liberal; sin embargo, al realizar nosotros el escrutinio de La Periódico-manía echamos en falta más de una publicación en la obra de Hartzenbusch. Las fuentes por él utilizadas, además de La Periódico-manía, permiten una visión en verdad detallada y muy minuciosa de la prensa madrileña, desde su aparición hasta el año 1870; sin embargo, como ya hemos indicado, existen ausencias a tenor de lo consultado en La Periódico-manía. La bibliografía utilizada por E. Hartzenbusch ${ }^{2}$ así como la relación de personas ${ }^{3}$ que contribuye-

1 Hartzendusch, Eugenio, Apuntes para un catálogo de periódicos madrileños, Madrid, Establecimiento Tipográfico Sucesores de Rivadeneyra, 1894.

2 SEMPERE GuARINos, Juan, Ensayo de una biblioteca española de los mejores escritores del reinado de Carlos III, Madrid, Imprenta Real, 1785-89; La Periódico-manía, Madrid, Imprentas de Collado y de la Viuda de Aznar, 1820-21; Boletín bibliográfico, Madrid, Imprentas de J. Sancha y del Hospicio, 1840-50 y 1860-67. AnTón Ramírez, Braulio, Diccionario de bibliografía agronómica, Madrid, Imprenta de Rivadeneyra, 1865. DEL CAMPO, José María, «Monografía de la prensa periodística de España», Los Sucesos, Madrid, julio-agosto, 1868. DE BONA, Francisco Javier, Anuario administrativo y estadístico de la provincia de Madrid para el ano 1868, Madrid, Tipografia del Hospicio, 1868-69. MAFFEI, Eugenio, y RÚA FIGUEROA, Ramón, Apuntes para una bibliografía española de libros, folletos... relativos al conocimiento y explotación de las riquezas minerales..., Madrid, Imprenta de J. M. Lapuente, 1871-72. GuERrERo, Teodoro, "Calendario español de las letras, las ciencias y las artes en el siglo XIX», Almanaque de la llustración, Madrid, 1875. PÉREZ DE GuZMAN, Juan, «Catálogo de ilustres periodistas españoles desde el siglo XVII», Almanaque de la Ilustración, Madrid, 1876. Almirante, José, Bibliografía militar de España, Madrid, Imprenta de M. Tello, 1876. MÉNDEZ ÁlVARo Francisco, Breves apuntes para la historia del periodismo médico farmacéutico en España, Madrid, Imprenta de E. Teodoro, 1883.

3 Manuel Tamayo y Baus, Jenaro Alenda, Cándido Bretón y Orozco, Ramón de Mesonero Romanos, Manuel M. a José de Galdó, Juan Pérez de Guzmán, Manuel Ossorio y Bernard, Julio Nombela, Felipe Pérez Boloque, Blas Araque, Manuel Ortiz de Pinedo, Nicolás Díaz y Pérez, Adolfo Llanos y Alcaraz, Eduardo Sánchez y Rubio, Leopoldo Martínez Reguera, Joaquín de Arce Bodega, José Landeira y Domínguez, Francisco Rispa Perpiñá, Enrique Prúgent, José M. ${ }^{a}$ Sbarbi, Julián Sabando, José M. ${ }^{a}$ Nogués, Constantino Román y Juan Eugenio Hartzenbusch. 
ron con noticias verbales o manuscritas en la elaboración del citado catálogo periodístico han hecho posible la realización de una obra que nos permite estudiar con toda suerte de detalles el periodismo madrileño desde sus orígenes. El cotejo entre el trabajo de Hartzenbusch y la relación de periódicos analizados por La Periódico-manía es indispensable en la elaboración de estas páginas, ya que el primero sirve de guía para nuestros propósitos. Existen también otros catálogos y obras ${ }^{4}$ de gran utilidad y valor, como el estudio de A. Asenjo ${ }^{5}$ y el titulado Catálogo de las publicaciones periódicas madrileñas existentes en la Hemeroteca Municipal de Madrid, 1661-1930. De igual manera la obra de Mesonero Romanos, en especial la titulada Memorias de un setentón ${ }^{6}$, es también imprescindible para el análisis de la prensa decimonónica. Gracias al Curioso Parlante sabemos, por ejemplo, que el abogado D. Francisco Camborda era el redactor de La Periódico-manía, desvelándose de esta manera el anonimato del principal colaborador del periódico.

La Periódico-manía, publicación eminentemente satírica, surge en la conocida libertad de prensa decretada en el Trienio Liberal. Durante esta época el panorama periodístico alcanza cotas difícilmente imaginables, pues en los tres años que precedieron el inicio del período constitucional tan sólo se publicaron La

4 Gomez APAricio, P., Historia del periodismo español, desde «La Gaceta de Madrid» (1661), hasta el destronamiento de Isabel II, Madrid, Editora Nacional, 1967. GrL NovAlES, A., «La prensa en el trienio liberal (1820-1823)» en Prensa y sociedad en España (1820-1936), Madrid, Ed. Cuadernos para el Diálogo, 1975. Zavala, I. M., «La prensa exaltada en el trienio constitucional: El Zurriago", Bulletin Hispanique, LXIX, 1967 y Románticos y socialistas. Prensa española del XIX, Madrid, Siglo XXI, 1972. DÉROZIER, A., «Relaciones entre Historia y Literatura a través de la producción periodística del Trienio Liberal (1820-23)», Actas del Cuarto Congreso Internacional de Hispanistas, Salamanca, 1982. Simón DíAZ, J., Madrid en su prensa en el siglo XIX, Madrid, Ayuntamiento e Instituto de Estudios Madrileños, 1981. Gallego Y BuRín, A., «Datos para la historia del periodismo español: una colección de periódicos del reinado de Fernando VII, 1820-1823» en Estudios eruditos in memoriam de A. Bonilla y San Martín, I, Madrid, 1927.

5 ASENJO, A., La prensa madrileña a través de los siglos (Apuntes para su historia desde el año 1661 al de 1925), Ayuntamiento de Madrid, 1933.

6 Mesonero Romanos, Ramón de, Memorias de un setentón, Madrid, BAE, 1967, vol. V, página 109. 
Crónica Científica y Literaria $^{7}$, Continuación del almacén de frutos literarios o semanario de obras inéditas ${ }^{8}$ y Miscelánea de comercio, artes y literatura ${ }^{9}$. La época más interesante en cuanto al número de periódicos corresponde a los años 1813 y 1814. En el año 1813 se publicaron El amante de la libertad civil ${ }^{10}$, El ciudadano imparcial ${ }^{11}$, Faramalla intermitente ${ }^{12}$, El Duende de Madrid ${ }^{13}$, El Patriota ${ }^{14}$, Atalaya de la Mancha en Madrid ${ }^{15}$, El amigo de la Ley ${ }^{16}$, El Fiscal patriótico de España ${ }^{17}$, El azote de los afrancesados y zeloso de la libertad de la patria ${ }^{18}$, El Redactor

7 Crónica científica y literaria, Madrid, Imprenta de Repullés, 1817-20. Comenzó a publicarse el 1 de abril de 1817, saliendo martes y viernes; en el número CCCIX (13 de marzo de 1820), tomó el título de El Constitucional: o sea Crónica científica, literaria y política, desde cuya fecha se hizo diario con carácter político liberal. Se encargaron de su publicación don Agustín de Letamendi, don Manuel Eduardo de Gorostiza y don José Joaquín de Mora.

8 Continuación del almacén de frutos literarios o semanarios de obras inéditas, Madrid, 181819, impreso por Repullés y redactado por Francisco Javier de Burgos.

9 Miscelánea de comercio, artes y literatura, Madrid, 1819-21. En un principio, salía los lunes, miércoles y viernes de cada semana; desde el 1 de junio de 1820 se convirtió en diario y se llamó Miscelánea de Comercio, Politica y Literatura. Su director fue don Francisco Javier de Burgos.

10 El amante de la libertad civil, Madrid, 1813, Imprenta de Villalpando.

11 El ciudadano imparcial, Madrid, 1813, Imprenta de la viuda de Barco. Salía los lunes y jueves de cada semana.

12 Faramalla intermitente, Madrid, 1813, Imp. de Álvarez, Postigo de San Martín. Sólo se publicaron cuatro números.

13 El Duende de Madrid, Madrid, 1813. Se anunció su salida bisemanal para el día 17 de noviembre del mismo año.

14 El Patriota, Madrid, 1812-13. Salia los miércoles y sábados. El director de esta publicación fue don José Mor de Fuentes.

15 Atalaya de la Mancha en Madrid, Madrid, 1813-15. Imprenta de F. de la Parte. Comenzó a publicarse el 13 de julio de 1815 y salía los martes y viernes. El 2 de abril de 1814 se hizo diario. A partir del 2 de enero de 1815 aparecía los lunes, miércoles y viernes. Fue un periódico político, vivo defensor del rey Fernando VII, dirigido por el P. Fr. Agustín de Castro.

16 El amigo de la Ley, Madrid, 1813. Semanal. Imprenta de Repullés, plazuela del Ángel. El número suelto costaba seis cuartos.

17 El Fiscal patriótico de España, Madrid, 1813-14. Imprenta de Villalpando. Salía los lunes y viernes de cada semana. Fue de espíritu católico y amante del rey Don Fernando VII. Su autor, según consta en la portada, era don Josef Manuel Jecebek.

18 El Azote de los afrancesados y zeloso de la libertad de la patria, Madrid, 1813. Imprenta de Repullés. 
general de España ${ }^{19}$, El Amigo del pueblo ${ }^{20}$, El Publicista espa$\tilde{n o l}^{21}$ y Quisicosa del Día ${ }^{22}$. En el año 1814 contabilizamos un total de quince periódicos, algunos de ellos de escasa duración. La relación es la siguiente: El Universal ${ }^{23}$, El Conciso ${ }^{24}$, La Abeja Madrileña ${ }^{25}$, El Procurador general de la Nación y del Rey ${ }^{26}, E l$ Tribuno del pueblo español ${ }^{27}$, La España libre ${ }^{28}$, El amante de la libertad civil ${ }^{29}$, El Reloxero Universal ${ }^{30}$, El Periódico ministerial intitulado Correo político y económico de las provincias de la Pe-

19 El Redactor general de España, Madrid, 1813-14, Imprenta de Repullés; y en la de Espinosa, 1821. Diario. Era político, de carácter liberal. Colaboraron Alcalá Galiano, el marqués de Miraflores y don Pedro Pascasio Fernández. Su redactor principal fue don Pedro Daza.

20 El Amigo del pueblo, Madrid, 1813. Se publicaba los martes y viernes en la Imprenta de la Compañía, por el regente Juan Josef Sigüenza y Vera. Cesó el 31 de diciembre del mismo año (n. $\left.{ }^{\circ} 43\right)$.

21 El Publicista Español, Madrid, 1813-14. Imp. de la Viuda de Vallín, calle de Borradores. Sin fecha fija de publicación.

22 Quisicosa del Día, Madrid, 1813-14. Imp. de Álvarez y Repullés. Publicó un total de veinticuatro números.

23 El Universal, Madrid, 1814. Diario. Imprenta de El Universal, calle del Arenal. Cesó el 11 de mayo de dicho año.

24 El conciso, Madrid, 1814. Diario. Empezó a publicarse en Cádiz el 24 de agosto de 1810 y continuó publicándose hasta el 24 de diciembre de 1813. En Madrid, empezó a publicarse el 16 de enero de 1814. Periódico de ideas liberales. Imprenta de Fuentenebro, calle de Jacometrezo.

25 La Abeja Madrileña, Madrid, 1814. Diario. Imprentas de Villalpando y de la Viuda de Vallín. Periódico liberal dirigido por don Bartolomé José Gallardo.

26 El Procurador general de la Nación y del Rey, Madrid, 1814-15. Imp. de F. Martínez Dávila. Diario. Empezó a publicarse en Cádiz en 1812-13. En junio de 1814 apareció con el título de El Procurador general del Rey y de la Nación.

27 El Tribuno del pueblo español, Madrid, 1814. Se publicaba los martes y viernes de cada semana en la Imprenta de Espinosa. Empezó a editarse en Cádiz, 1812-13, en la Imprenta Tormentaria, a cargo de Juan Domingo Villegas.

28 La España libre, Madrid, 1814. Diario. Imprenta de Fuentenebro, calle de Jacometrezo. Comenzó el 15 de febrero y cesó el 21 del mismo mes y año.

29 El amante de la libertad civil, Madrid, 1814. Diario. Tuvo su origen en Cádiz y empezó a publicarse en Madrid a partir del 1 de marzo. Del 6 de abril en adelante salía sólo una vez a la semana.

30 El Reloxero Universal, Madrid, 1814. Comenzó a publicarse el 12 de abril, apareciendo los lunes, miércoles y viernes. 
nínsula ${ }^{31}$, Mercurio español $^{32}$, Correo General ${ }^{33}$, El Sol $^{34}$, El filósofo de antaño en su gabinete ${ }^{35}$, Lucindo $^{36}$ y Diario de las Cortes $^{37}$.

La Periódico-manía empieza a publicarse en el año 1820, sin fecha ni período fijo de publicación. El número suelto costaba trece cuartos ${ }^{38}$. Cada número tenía alrededor de veinticuatro páginas; incluso, existen números que no sobrepasan el total de veinte, como el número 18 , aunque la tónica general sea de veintitrés o veinticuatro páginas. Las medidas del mismo son de $0^{\mathrm{m}}, 118 \times 0^{\mathrm{m}}, 066$, imprimiéndose en las Imprentas de Collado, de la Viuda de Aznar a cargo de José Pío León, y de El Constitucional por Antonio Fernández. Al final de cada número aparece a pie de página la ciudad en la que se imprimió el periódico -Madrid-, la imprenta correspondiente y el año de impresión. Tan sólo se publicaron un total de cuarenta y tres números, sin especificarse día ni mes, únicamente el número correspondiente sirve de identificación al lector.

\section{En las páginas de La Periódico-manía encontramos numero-}

31 El Periódico ministerial intitulado Correo político y económico de las provincias de la Penísula, Madrid, 1814. Imprenta Nacional. Periódico redactado conforme a las correspondencias de los jefes políticos y que tenía por objeto dar a conocer al público el estado de los pueblos.

32 Mercurio español. Colección de noticias políticas, mercantiles y literarias, Madrid, 1814. Diario. Imprenta de Repullés.

33 Correo General, Madrid, 1814. Diario. Imprenta de Repullés. Concedía mayor atención a las noticias extranjeras que a las nacionales, y en la sección denominada «Variedades» aparecen artículos no políticos de escasa importancia.

34 El Sol, Madrid, 1814. Diario. Imprenta de Fuentenebro. Comenzó el 1 de noviembre de 1814 y cesó con el número 36, 6 de diciembre del mismo año.

35 El filósofo de antaño en su gabinete, Madrid, 1814. Semanal. Imprenta de F. Martínez. Turo este periódico una primera época publicada en Cádiz, año 1813, que comprende 24 números.

36 Lucindo. Ayes de los españoles cautivos, y consuelo que les envían los que se dicen exclusivamente patriotas, Madrid, 1814. Impreso por F. Martínez Dávila. Lucindo, seudónimo de don Justo Pastor Pérez, redactor del periódico.

37 Diario de las Cortes, Madrid, imprenta especial de las Cortes, por don García Campoy, Imprenta Nacional, y en la de J. A. García, 1814, 1820-1823, 1834-1870.

38 La cita textual sobre el precio del periódico dice así: «Cada cual soltará sus trece cuartitos, según tarifa, porque así se han empezado a vender otros cuadernos, y es justo seguir la loable; y porque este periódico es una propiedad nuestra, y cada uno vende como le acomoda; y porque si no se vendiere (lo que Dios no permita), nos quedaríamos gastados, aburridos, y sin oficion, La Periódico-manía, n. ${ }^{\circ}$, pp. 6-7. 
sas alusiones a la venta del periódico. La cita más completa corresponde al número 18 , pues no sólo se cita el impresor sino también las correspondientes librerías y puntos de venta en el Madrid de los años 1820 y 1821: «Se hallará en Madrid en las librerías de Collado, calle de la Montera; de Brun, frente a las Gradas de San Felipe el Real; de Sojo y de Sanz, calle de Carretas; de Cruz y Miyar, calle del Príncipe; de Villa, plazuela de Santo Domingo, y de Minutria, calle de Toledo». ${ }^{39}$

En La Periódico-manía se hace alusión en sucesivas ocasiones a los autores de la publicación, autores que el lector desconoce, pues en ningún momento figuran los nombres de los mismos. Sí sabemos que la redacción del mismo la forman dos personas, como se nos informa en el número 2 con ocasión del reparto de ganancias que el número ha proporcionado a sus autores. Se nos dice que entre los dos redactores han conseguido la fabulosa suma de treinta duros, cifra que nos parece exagerada y que tal vez obedeciera a crear confusión entre la legión de periodistas que se veían obligados a poner punto final a su periódico por falta de recursos económicos.

En las páginas de La Periódico-manía el lector podrá encontrar información sobre el entorno, fines y propósitos del periodismo de la época. Noticias acerca de la precaria situación económica de los periodistas, hombres que no sólo viven en continua estrechez monetaria sino que también se ven aquejados de la penuria económica de que hacen gala los editores y libreros en general. La Periódico-manía presume de ser un periódico opulento, aunque la realidad, tal vez, sea otra; lo cierto es que en casi todos los números de la publicación encontramos alusiones al mal del periodismo de los años veinte: la perentoriedad del periodista. A tenor de lo leído en La Periódico-manía podemos afirmar que el comienzo del Trienio Liberal provoca una auténtica epidemia periodística, consecuencia lógica de la libertad de imprenta, pero desproporcionada en su calidad, en sus fines y en sus propósitos. De todo este mare mágnum periodístico La Periódico-manía afirmará con humor lo siguiente:

39 La periódico-mania, n. ${ }^{\circ} 18$, p. 19. 
¡Todo es confusión y trastorno en el reino periodístico...! ¡Tantos hermanos muertos y epitafiados...! ¡Endeble es la cortadura! El Enemigo de la Esclavitud se ha transformado en plebeyo. El Constitucional se ha hecho gaceta. El Publicista padece flatos histéricos. El Conservador ha mudado de nido: ya es chismógrafo y va a ser acusador. El Mudito da voces en valde. El Universal, que antes enfadaba por su pesadez, es ya tan ligero como el cojo de Málaga. La Miscelánea se desatacó desde que la atacaron. La Ley vende rabanitos tiernos en el rastro. La Frailomanía habita en el colegio trilinguae. La nueva Gaceta Ministerial impugna las ideas de la que acabó. El Pobrecito Holgazán se aplica a un oficio honrado. La Sociedad de Lorencini se ha mudado. El nuevo Gabinete de lectura se ocupa de borrar de su lista muchos platos indigestos. Dentro de poco tiempo sólo tendrá para dar de comer a los literatos el Diario caldosito, la Gaceta con más hueso que carne, el Universal aperdigado, y la Miscelánea de postre. Al que quiera café se le servirá con el Vigilante, que quita el sueño, y al que guste de licores se le darán las Minervas para que pueda relamerse ${ }^{40}$.

La Periódico-manía, publicación eminentemente satírica, suele iniciar los números con una cita, nota o epígrafe alusivo a la intención del número correspondiente. No es extraño este recurso entre los periodistas de la época, pues la casi totalidad de los escritores lo emplean no sólo para encabezar sus artículos periodísticos o de costumbres, sino también en los sucesivos capítulos de las novelas históricas. El mismo Larra lo utilizará indistintamente tanto en su novela El doncel de don Enrique el Doliente como en sus artículos periodísticos. Este recurso obedece, pues, a una moda imperante en la época, recurso que irá desapareciendo a mediados del siglo XIX. Tras esta nota introductoria La Periódico-manía suele insertar sutiles y mordaces digresiones sobre el panorama periodístico de la época, de los problemas de financiación y del lamentable estado de las publicaciones. Se trata de un panorama sombrio descrito con mordacidad e ironía en el que escasas publicaciones escapan a su sátira. No faltan tampoco los ataques contra los periodistas que vulneran los principios constitucionales ${ }^{41}$, proclamándose acérrimo defensor de la libertad de

40 Ibid., n. ${ }^{\circ} 9$, pp. $3-4$
41 Ibíd., n. 
imprenta ${ }^{42}$ y vituperando todo tipo de folletos y publicaciones que atentaran contra estas premisas imprescindibles e inherentes a la condición humana. En realidad La Periódico-manía no deja títere con cabeza, pues su mordacidad acosa a todas las publicaciones de la época y si en un principio puede parecer respetuoso con las publicaciones coetáneas, no demorará mucho tiempo sus furibundas diatribas contra la prensa de la época; e incluso, si en un momento se muestra respetuoso con el clero, no tardará en censurar a los representantes de la Iglesia. Tres son los principios respetados por La Periódico-manía: la Constitución, la libertad de imprenta y la Monarquía. La figura del monarca como guardián y defensor de la Constitución, tal como figura en el Manifiesto publicado el 10 de marzo de 1820 en el que, entre otras cosas, Fernando VII jura que será su más firme defensor, es la postura que defiende La Periodico-manía, publicación que al tener una existencia efímera no pudo analizar desde sus páginas el cambio de la monarquía constitucional que desembocó en una monarquía absolutista.

Si estas digresiones nos proporcionan un informe general sobre los asuntos más importantes del momento, más tarde los redactores de La Periódico-manía analizarán las publicaciones de la época. Desde su singular óptica desfilan todos los periódicos editados durante los años 1820 y 1821, analizando su ideología, pertenencia política, autores e, incluso, la financiación de los mismos. Lanzará sus pronósticos a la manera de Torres Villarroel, vaticinando su fatal desenlace: la muerte del periódico. Los epitafios de La Periódico-manía son de lo más agudo y singular. Cada periódico de Madrid de la época que sucumbe por falta de suscriptores o por escasez de medios económicos suele tener su epitafio en las páginas de La Periódico-manía. Circunstancia que convierte al periódico en auténtico cementerio periodístico, como tendremos ocasión de ver.

Si todos estos factores son imprescindibles para conocer el alcance de la publicación, no menos importante es analizar su credo periodístico y el propósito que motivó a sus autores a editarla.

42 Ibid., n. ${ }^{\circ}$ 5, p. 3. 
En el primer número del periódico se afirma que los redactores se proponen «en este papel dar una idea de todos los periódicos que se han publicado [...] que hablarán también de los que hasta ahora han muerto, de los que están con los frailes a la cabeza y de los que morirán” ${ }^{43}$, y a renglón seguido lo siguiente:

Se aplaudirá lo bueno; criticaráse lo malo; se omitirá lo indiferente; se despreciarán las paparruchadas, y, en una palabra, se adoptará lo caliente, lo templado y lo fresco, conforme a la estación y a los males de que adolezcan dichos periódicos. O han de ir derechos, esto es, constitucionalmente, o no habrá hora de paz, ni quedará títere sin cabeza. A lo Gallardo. ${ }^{44}$

A partir del primer número desfilan un sinfín de publicaciones, como El Despertador, Espejo de las Españas, La Ley, El Indio liberal, Verdad y patriotismo, El Enemigo de la esclavitud, La Colmena, El Mensajero, La Cotorrita, El Sol, etc. Si La Periódico-manía reseña y analiza todo el espectro periodístico de la época mordaz y concisamente, algunos periódicos merecen la especial atención del nuestro. La redacción de La Periódicomanía suele recoger el nacimiento y muerte del periódico, intercalando entre sus números algún comentario relativo a la ideología y propósito de la publicación; sin embargo, cuando la publicación adquiere importancia, tanto por su financiación como por el alcance editorial, La Periódico-manía suele analizarla en casi todos sus números. Esto, precisamente, ocurre con El Conservador o El Universal, periódicos que a tenor de lo analizado en $L a$ Periódico-manía son los más citados.

La Periódico-manía dedica el primer epitafio al periódico $E l$ Despertador, publicación que tuvo una breve existencia. El estilo festivo y zumbón de La Periódico-manía se deja sentir en los siguientes versos:

43 Ibid., n. ${ }^{\circ}$ 1, pp. $3-4$.
44 Ibid., n. ${ }^{\circ}$ 1, p. 4. 
Ya podéis dormilones

Dar tremendos ronquidos,

Que los despertadores

Se han quedado dormidos.

Si del profundo sueño

En que están sumergidos

No vuelven, si no cobran

Otra vez sus sentidos, Enterradlos entonces, $Y$ en su sepulcro frío

Poned este epitafio

De su memoria digno

\section{Epitafio}

Aquí yace sepultado

(¡Oh qué terrible dolor!)

Quien siendo despertador

A ninguno ha despertado.

Muy breve fue su reinado,

Murió porque era mortal.

No hay que buscar a su mal

Achaques de indigestión

Si ya la anti-repleción

No le dio el golpe fatal. ${ }^{45}$

El Espejo de las Españas es otra rara curiosidad bibliográfica. Periódico del que sólo tenemos noticias gracias a La Periódico-manía, de ahí que sepamos que se vendía los domingos en la librería de Paz. En los cinco números ya publicados, incluso el del prospecto, que fue el primero, explica a los lectores que parte de las ganancias de la venta de la publicación van destinadas a socorrer a las víctimas de Cádiz. La Periódico-manía vaticina su muerte en muy corto plazo, a tenor de lo publicado en estos cinco números. El Espejo de las Españas tan sólo publicó un número más, circunstancia que provoca el regocijo entre los redactores de La Periódico-manía. El epitafio dice así:

Aquí yace el Espejo, asesinado por la feroz Periódico-manía, que siendo de su misma cofradía sus azarosos días ha abreviado. 


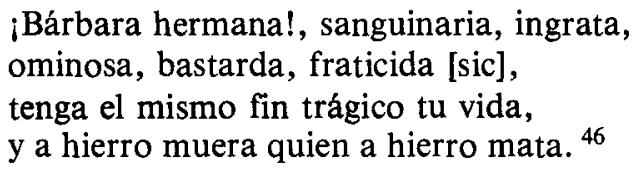

La escasa acogida de El Espejo de las Españas se debió, a juzgar por las páginas de La Periódico-manía, a la dudosa erudición y filantropía de sus promotores, así como a sus ideas barnizadas con el espíritu de la ilustración que lo hacían prácticamente inaccesible al lector de la época. Según La Periódico-manía llegó a provocar indigestiones y náuseas.

Otra publicación de suma rareza bibliográfica reseñada en $L a$ Periódico-manía es El Indio liberal, no citado por ningún catálogo sobre prensa, ni siquiera en el conocido Apuntes de un catálogo... de Hartzenbusch. Por nuestro periódico sabemos que empezó a editarse el 27 de abril de 1820 . Cesa el 4 de mayo del mismo año, publicándose tan sólo cuatro números. Los temas políticos e históricos eran lo más acertado de la publicación. La Periódico-manía lo describe como periódico profundo, correcto en la sintaxis y de ideas nada vulgares, no explicándose su prematura muerte. El epitafio dedicado al Indio Liberal es de los más concisos que aparecen en La Periódico-manía:

\author{
Murió el Indio liberal, \\ requiescat in pace, amén. \\ A nadie supo hacer mal; \\ pero tampoco hizo un bien. ${ }^{47}$
}

La Ley es otra de las publicaciones del Trienio Liberal de la que no se tienen noticias. La Periódico-manía le presta gran aten- 
ción, pues son varios los números en que aparece La Ley detenidamente analizada. Sabemos por nuestro periódico que llegó a publicar veintinueve números, editándose en la imprenta de Sancha. La Ley, a tenor de lo escrito en La Periódico-manía, es un periódico insolente que llegó a insultar no sólo a las más altas jerarquías de la época, sino también a los lectores más humildes. Ataca a la Constitución y a sus representantes, a la par que ofrece un panorama sombrío y desolador:

No es posible analizar las expresiones que vierte en descrédito de los mismos diputados; presenta la tranquila situación que disfrutamos bajo los más sombríos colores; insulta a los beneméritos hijos de la patria que han padecido por ella en los últimos seis años toda clase de males y calamidades; los pinta toscamente como ineptos y cuando hasta las demás naciones han reconocido sus virtudes y sus talentos. ${ }^{48}$

De igual forma La Ley vitupera al monarca - por aquel entonces- constitucional, circunstancia que provoca las iras de los redactores de La Periódico-manía. A tenor de lo escrito en este periódico creemos que La Ley fue una publicación antimonárquica y no anticonstitucional, que supo ver el turbio rumbo político de Fernando VII. Lo cierto es que los ataques al monarca provocaron su cese de inmediato, requisándose el último ejemplar $-\mathrm{N} .{ }^{\circ} 29-$ que censuraba, precisamente, la figura del rey y a los representantes parlamentarios. La Periódico-manía lo describe con duras y sarcásticas palabras. Cuando La Ley desaparece se pregunta lo siguiente:

¿Y dónde la colocaremos? En un muladar sería lo mejor, para que se la comieran los lobos; pero valga la caridad... Echémosla provisionalmente en un hoyo, que después no faltará quien saque sus huesos, los queme y esparza por el aire las cenizas. Entretanto recuerde su paradero el siguiente 


\section{EPITAFIO}

Periódico fue nefando, chabacano, escandaloso, la Ley que hoy estás mirando arrojada en este foso.

Ha sido muy celebrada su muerte (;cruel destino!), aplaudida y festejada como muerte de cochino. ${ }^{49}$

El periódico La verdad y Patriotismo constitucional, analizado también por La Periódico-manía, es un curioso ejemplar no citado en los catálogos sobre publicaciones periódicas madrileñas. A juzgar por lo recogido en nuestro periódico llegó a publicar un total de veinte números -el último el 16 de mayo de 1820 - La impresión corrió a cargo del editor Cano y la venta del mismo se llevaba a cabo en el establecimiento del librero Matute. Grandes debieron de ser las deudas contraídas por los redactores del periódico a juzgar por el tono irónico de $L a$ Periódico-manía, pues por lo visto tan sólo «la pluma y el tintero, únicos bienes que le restan, no pueden ser embargados con arreglo a la ley»..$^{50}$

En el último número de la publicación arremete contra los impresores, prensistas, cajistas y libreros por las deudas contraídas. El mismo epitafio se referirá a la penuria económica del periódico:

La Verdad murió atrampada

y el Patriotismo empeñado, ella yace aquí enterrada, y él yace aquí sepultado.

Aunque indignos pecadores nunca fueron petardistas, díganlo los impresores, los libreros y cajistas.

49 Ibid., n. ${ }^{\circ} 11$, pp. 9-10.

50 Ibíd., n. ${ }^{\circ} 4$, p. 10. 
Lo que es con trampas morir

viene a ser moda en el día,

y esta moda ha de seguir

la Periódico-manía. ${ }^{51}$

Si hemos hecho alusión a la falta de medios económicos para la financiación del periódico en el Trienio Constitucional, es, sencillamente, porque toda la prensa de esta época vive agobiada por la falta de medios. Cabe pensar que la empresa más ruinosa era el periódico, por supuesto hacemos alusión directa a los redactores del mismo, más que a los editores o libreros. Un ejemplo más sería el periódico titulado El Enemigo de la esclavitud. Gracias a La Periódico-manía sabemos que empezó su carrera periodística con el título de Reforma que debe adoptar la Junta Provisional de Madrid para asegurar la libertad del ciudadano. Se vendía, al igual que el anterior periódico, en el establecimiento del librero Matute, publicándose tan sólo ocho números. Murió, según La Periódico-manía, «de magro, por ser afecto a los viernes» y endeudado hasta límites insospechados. El estilo grandilocuente de El Enemigo de la esclavitud aparece destacado por $L a$ Periódico-manía, ya que no sólo se complace en afirmarlo, sino que transcribe un párrafo del periódico como si de un acta notarial se tratara para demostrarlo así a sus lectores. Las «expresiones felices» que transcribe La Periódico-manía del periódico $E l$ Enemigo de la esclavitud nos recuerdan aquellos textos sacros tan sutilmente censurados por Isla en su Fray Gerundio Campazas:

Ominosos siglos; ominosa contemporización; ominoso letargo; el bramido de las preocupaciones; la libertad del pensamiento perdida y recobrada; el plantío del honor; la miserable tranquilla de circunstancias actuales; la fuerza majestuosa de los rayos; las hachas benéficas; la discreción de los hados; la sombra de la nulidad. ${ }^{52}$

El periódico La Colmena no se escapa tampoco de los ataques de La Periódico-manía. Esta publicación se imprimió pri-

51 Ibíd., n. ${ }^{\circ} 4$, p. 12.

52 Ibid., n. ${ }^{\circ} 4$, p. 16. 
mero en la imprenta de Repullés y después en la de la Viuda de Aznar. La Colmena constaba de ocho páginas de $0^{\mathrm{m}}, 157$ x $0^{\mathrm{m}}, 094$ «en papel de a folio y tiesecilla en forma de gaceta» según $\mathrm{La} \mathrm{Pe-}$ riódico-manía. Empezó a publicarse el 17 de marzo de 1820. El 8 de mayo se hizo diario, dejándose de publicar el 14 de junio de 1820. Esta publicación liberal fue redactada por don Félix Mejía, escritor que se uniría a don Benigno Morales para la redacción del conocido periódico El Zurriago, de insolente procacidad. El lema de esta publicación es bastante elocuente:

No entendemos de razones, moderación ni embelecos; a todo el que se deslice zurriagazo y tente tieso.

Don Félix Mejía, a tenor de lo descrito en La Periódico-manía, tuvo serias dificultades para publicar La Colmena. En especial, la económica fue la causa de su cese. Nació el periódico con escasez de medios y murió endeudado. Según La Periódico-manía «acabó de dar la causa del general Porlier en el día 14 del corriente, y sin decir oste ni moste se quedó muerto. ${ }^{53}$ Esta publicación tuvo escasa acogida entre el público de la época, pues según nuestro periódico «los ejemplares de La Colmena no salen de la librería, donde pueden verse en paquetes de resma casi completa, en tanta copia, que si se colocasen perpendicularmente, sacarían la cresta por encima del pico de Tenerife»" ${ }^{54}$. Más tarde La Periódico-manía en su número 8, en una sección titulada Noticias, nos dice que el ciudadano Antonio Baldaracete, «comisionado del confitero de Villatobas», escribe a los editores de La Colmena comunicándoles la compra de todos los ejemplares sobrantes a

53 Ibid., n. ${ }^{\circ}$ 6, p. 12.

54 Ibid., n. ${ }^{\circ} 6$, pp. 12-13. 
veinte reales resma. Una vez más La Periódico-manía dedicará su epitafio al periódico recién fallecido:

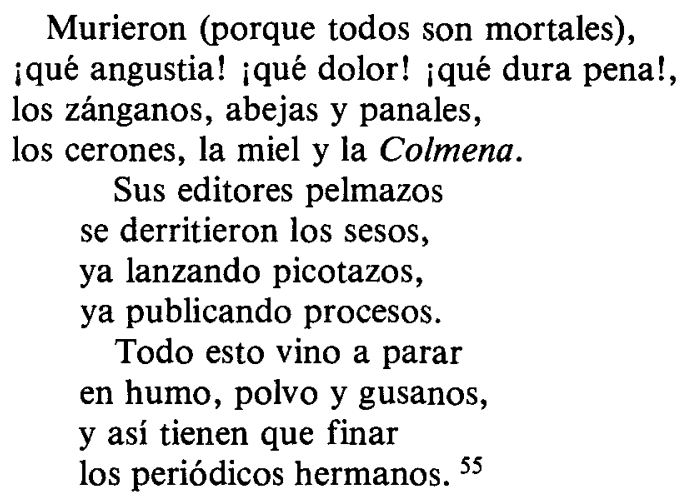

El Mensajero es la siguiente publicación analizada por $\mathrm{LaPe}$ riódico-manía. Este periódico llevaba el ambicioso subtítulo de Diario universal de política, literatura y artes, empezó a publicarse el 15 de mayo de 1820 y cesó el 30 de junio del mismo año. Creemos que el director de la misma sería don Pedro M. ${ }^{\mathrm{a}}$ de Olive. La Periódico-manía no cita a ningún autor por su nombre y apellidos, sin embargo, sí nos dice que «este caro hermano por el año de 1805 ya redactaba la Minerva Española y lo lucía. Son infinitas las novelas que ha traducido, regularmente saldrán a la luz muy en breve, porque ahora le sobra tiempo para corregirlas» ${ }^{56}$. La Minerva Española empezó a publicarse el primero de octubre de 1805 en la imprenta de Vega; más tarde en la de Núñez y, por último, en la de Ibarra. Constaba de ocho páginas de $0^{\mathrm{m}}, 140 \times 0^{\mathrm{m}}, 080$. En un principio salía dos veces por semana, más tarde se convirtió en semanario y, finalmente, se publicó una vez al mes. El último número corresponde al mes de octubre de 1818. Tanto en los medios periodísticos como editoriales de la época sabían que tras esta publicación se encontraba el escritor don Pedro M. ${ }^{a}$ de Olive.

El Mensajero, que se vendía a ocho cuartos, según La Perió-

55 Ibíd., n. ${ }^{\circ}$ 6, p. 14.

56 Ibid., n. ${ }^{\circ} 8$, p. 14. 
dico-manía, está herido de muerte y por mucho que intente sobrevivir y convocar a sus suscriptores para remediar el fatal desenlace, su muerte está próxima. La sátira zumbona, sarcástica e hiriente surge de nuevo en las páginas de La Periódico-manía, al afirmar que El Mensajero «come de toda clase de viandas literarias, pero la flaqueza de su estómago no le permite digerirlas, y antes de hacer cocción, las vomita avinagradas $\gg{ }^{57}$.

A tenor de lo leído en La Periódico-manía, El Mensajero se endeudó de tal manera que la dueña de la imprenta, Viuda de López, «ha tenido que tomar el partido de dedicarse a imprimir los romances de Pedro Cadenas y algunas cancioncillas de ciegos». ${ }^{58}$ La implacable mordacidad de La Periódico-manía se dejará sentir una vez más en sus conocidos epitafios. El dedicado a El Mensajero pondrá de manifiesto la precariedad económica de la prensa del Trienio Liberal:

\footnotetext{
Desde el número primero se dejaba discurrir que iba bien pronto a morir el infeliz Mensajero.

Que la falta de dinero le mató, es muy evidente: ¡Válgame Dios, cuánta gente del gremio periodical va a sucumbir a este mal...! No queda ningún viviente. ${ }^{59}$
}

Juzgar el Trienio Liberal sin el testimonio de La Periódicomanía sería empresa harto difícil, aun siendo conscientes del peculiar subjetivismo de que hacen gala sus redactores. Una vez desbrozada su insidia y también su procacidad obtendremos datos de gran importancia para el análisis de la prensa madrileña en este conocido período constitucional. 